\title{
Breast Morphometry in Senegalese Women: Study on a Sample of 118 Subjects
}

\section{Ndeye Bigue Mar ${ }^{1 *}$, Assane Ndiaye ${ }^{2}$, Aïnina Ndiaye ${ }^{1}$, Karim Yacouba Garba ${ }^{1}$, Magaye Gaye ${ }^{1}$, Sokhna Astou Gawane Thiam ${ }^{1}$, Issa Dior Seck ${ }^{1}$, Racky Wade', Jean Marc Ndiaga Ndoye1, Mamadou Diop', Abdoulaye Ndiaye ${ }^{1}$}

\author{
${ }^{1}$ Laboratory of Anatomy and Organogenesis, Faculty of Medicine, Pharmacy and Dentistry, Cheikh Anta Diop University, \\ Dakar, Sénégal \\ ${ }^{2}$ Training and Research Unit in Health Sciences, Assane Seck University of Ziguinchor, Ziguinchor, Sénégal \\ Email: ^biguemarmbaye@yahoo.fr
}

How to cite this paper: Mar, N.B., Ndiaye, A., Ndiaye, A., Garba, K.Y., Gaye, M., Thiam, S.A.G., Seck, I.D., Wade, R., Ndoye, J.M.N., Diop, M. and Ndiaye, A. (2020) Breast Morphometry in Senegalese Women: Study on a Sample of 118 Subjects. Advances in Breast Cancer Research, 9, 13-20.

https://doi.org/10.4236/abcr.2020.92002

Received: January 26, 2020

Accepted: March 29, 2020

Published: April 1, 2020

Copyright $\odot 2020$ by author(s) and Scientific Research Publishing Inc. This work is licensed under the Creative Commons Attribution International License (CC BY 4.0).

http://creativecommons.org/licenses/by/4.0/ (c) (i) Open Access

\begin{abstract}
Nowadays, women are more and more resorting to breast surgery for the purposes of isolated esthetics or within the framework of a mammectomy for tumor with its cohort of psychological problems post mutilation often requiring reconstruction. In context of breast cancer increase in Senegal, we have carried out breast morphology in female subjects of the Sahelian type in order to contribute to the development of a morphological database for reconstruction, reduction or breast augmentation. It was a prospective study on $118 \mathrm{fe}$ male subjects received at Cancer Institute for screening. They were divided into two groups (age $\leq 40$ years and age $>40$ years). Subjects' morphometric variables were collected in anatomical position and correlated with age, parity, obesity and genital activity using. Fifty six subjects $(47.5 \%)$ were over 40 years of age. There were 40 multiparous (33.9\%). Fifteen subjects (12.7\%) and six subjects $(5 \%)$ were obese and morbidly obese, respectively. Subjects in genital activity were 34 (29\%). The overall average size of the areola was $4.3 \pm$ $1.5 \mathrm{~cm}$. The nipple was low located with an average of $7.2 \pm 3.5 \mathrm{~cm}$. The diameters mentioned above increased significantly with age and body mass index, for $\mathrm{p}$-values $<0.05$, with the exception of the vertical diameter. Breast diameters were greater in postmenopausal women. Morphometry of Sahelian-type women's breast is strongly influenced by socio-demographic data, hence the need to take it into account during reconstruction, reduction or breast augmentation surgeries in Senegal.
\end{abstract}

\section{Keywords}

Breasts, Morphometry, Surgery, Sahelian Woman 


\section{Introduction}

Breast represents a cardinal symbol of beauty, sensuality and sexuality of a woman. Its morphology is subject to great variability in its dimensions, especially after puberty. This morphology also depends on family, racial and ethnic specificities [1] [2] [3] [4]. Note also that women are increasingly resorting to breast surgery for isolated aesthetical or as part of therapy with his cohort of post-mutilation psychological problems, especially in the context of a resurgence of breast cancer in Senegal (the number of cases increased from 749 in 2010 to 3826 in 2017 according to data from the Registry of the Institute of Cancer DAKAR). The efficiency of breast plastic surgery worldwide is fueled by studies on morphometry [5] [6] [7]. With the rise of plastic surgery in Senegal, it became necessary to focus on the study of breast morphology in women. The aim of this work was to specify the morphometric variations of the breast as a function of socio-demographic data in 118 Senegalese female subjects to propose a morphological database for breast reconstruction, reduction or augmentation.

\section{Subjects and Method}

\subsection{Subjects}

They were 118 Senegalese melanoderm women who consulted at the Cancer Institute for mastodynia or came to do a screening mammography at the Radiology Department of Aristide Le Dantec Hospital from the beginning of January 2013 till the end of September 2013. Were not included, all women with breast disease, breast surgery and pregnant or lactating women.

\subsection{Method}

After her free consent, the subject was stripped to the waist and the measurements were taken in an anatomical position. Thus for each subject, we noted on sheet, socio-demographic and morphometric data:

Age, parity (the number of pregnancies completed), genital activity (menopausal or premenopausal), weight in $\mathrm{kg}$ (using a scale), size in $\mathrm{cm}$ (using a height rod), the body mass index (BMI) in $\mathrm{kg} / \mathrm{m}^{2}$ (normal: BMI 18 to 24.9; overweight: BMI 25 to 29.9; obesity: BMI 30 to 39.9; morbid obesity: BMI from 40).

For each breast, the following measurements were made: largest horizontal diameter in $\mathrm{cm}$ (Figure 1), vertical diameter: distance from the lower breast to the

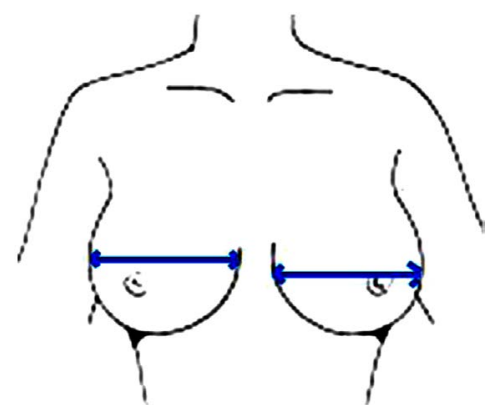

Figure 1. Horizontal diameter measurement. 
upper breast determined by the slight upward pushing of the breast in $\mathrm{cm}$ (Figure 2), areola size in $\mathrm{cm}$ (largest diameter of the areola) (Figure 3), position of the nipple determined by its relative location to the median of the vertical line connecting the acromion to the lateral epicondyle. The nipple is said to be high located when it is above the median and low when it is below the latter (Figure 4). All data was entered into an Excel file and the statistical analyzes made using the Epi info 7 software.

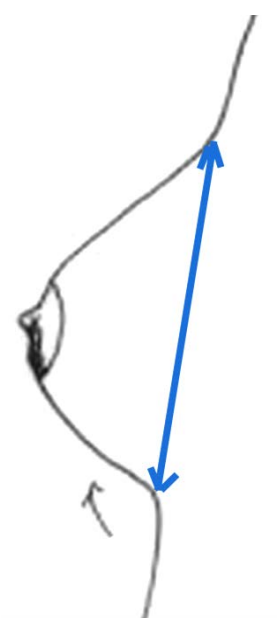

Figure 2. Vertical diameter measurement.

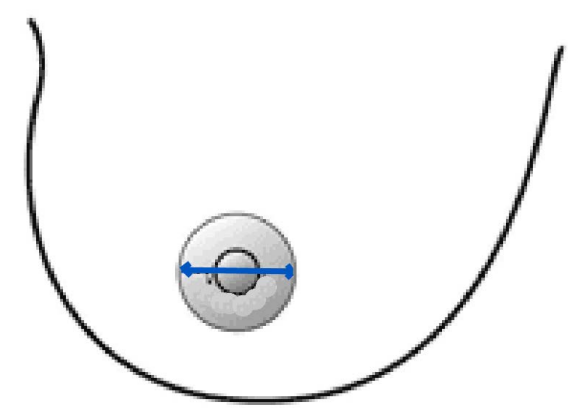

Figure 3. Largest diameter of the areola measurement.

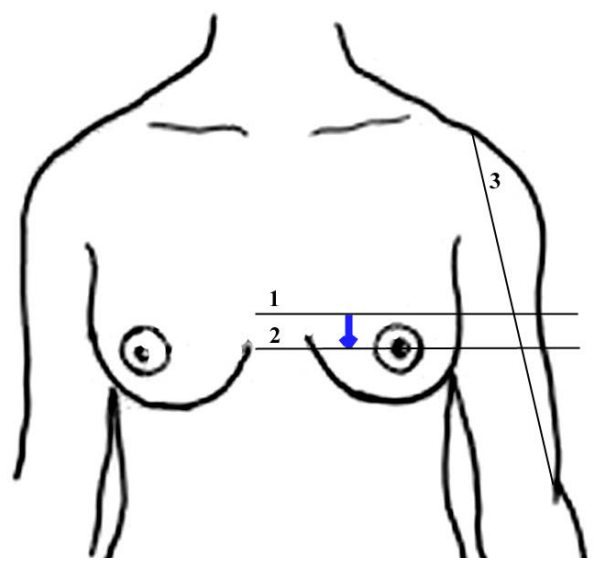

Figure 4. Position of the nipple measurement. 


\subsection{Statistical Analyzes}

Two age groups were established for the purposes of statistical correlation: group 1 (age $\leq 40$ years) and group 2 (age $>40$ years).

Qualitative variables were expressed in proportions and the quantitative ones, on average with standard deviation. According to the validity conditions, the chi-square test was used to study the association between two qualitative variables. For the comparison of means or quantitative variables, Student and the ANOVA tests were respectively used to compare two means or more than two means.

All the statistical calculations were carried out using a confidence level of $95 \%$ and a threshold value of $\mathrm{P}$ equal to 0.05 . At the $95 \%$ confidence level, the test was statistically significant if the threshold value of $\mathrm{P}$ was less than 0.05 .

\section{Results}

\subsection{Socio-Demographic Data}

Table 1 below summarizes the socio-demographic data expressed as a percentage. The population aged under 40 was larger with a percentage of $52.5 \%$.

\subsection{Breast Morphometric Data}

Table 2 highlights the averages of the breast morphometric data.

\subsection{Correlation Tests}

Table 3 illustrates the variations of the different diameters of the breasts depending on the age.

There is an increase in the average horizontal diameter as a function of age.

The breast diameters measured (vertical, horizontal and areolar) increased statistically significantly with BMI except the vertical diameter of the right breast (Table 4).

Table 1. Sociodemographic data expressed as a percentage.

\begin{tabular}{cccc}
\hline \multirow{2}{*}{ Groups } & & Numbers & Percentages (\%) \\
& 1 & 62 & 52.5 \\
\multirow{2}{*}{ Genital activity } & 2 & 56 & 47.5 \\
& postmenopausal & 34 & 29 \\
& Not menopausal & 84 & 71 \\
\hline \multirow{2}{*}{ BMI } & Normal & 65 & 55 \\
& Overweight & 32 & 27.2 \\
& Obesity & 15 & 12.7 \\
& Morbid obesity & 6 & 5 \\
\hline \multirow{2}{*}{ Parity } & Nulliparous & 26 & 22.03 \\
& pauciparous & 52 & 44.07 \\
& Multiparous & 40 & 33.9
\end{tabular}


Table 2. Breast morphometric data.

\begin{tabular}{cccc}
\hline & Right breast & $\begin{array}{c}\text { Averages } \pm \text { standard } \\
\text { deviation }\end{array}$ & $\begin{array}{c}\text { Averages } \pm \text { standard } \\
\text { deviation }\end{array}$ \\
\hline $\begin{array}{c}\text { Horizontal } \\
\text { diameter } \\
(\mathrm{cm})\end{array}$ & Left breast & $16.6 \pm 4.1$ & $16.9 \pm 4.1$ \\
\hline $\begin{array}{c}\text { Vertical diameter } \\
(\mathrm{cm})\end{array}$ & Right breast & $7.7 \pm 2.1$ & $7.9 \pm 2.1$ \\
\hline $\begin{array}{c}\text { Areola size } \\
(\mathrm{cm})\end{array}$ & Left breast & $8 \pm 2.1$ & $4.3 \pm 1.5$ \\
\hline & Right breast & $4.1 \pm 1.5$ & $3.2 \pm 0.5$ \\
\hline \begin{tabular}{c} 
Nipple position \\
\cline { 2 - 4 }
\end{tabular} & Left breast & $4.4 \pm 1.6$ & \\
\cline { 2 - 5 } & Right breast & $2.8 \pm 0.5$ & $9.5 \pm 3.5$ \\
\hline
\end{tabular}

Table 3. Variation of the means of the different diameters according to age.

\begin{tabular}{|c|c|c|c|c|}
\hline & & \multicolumn{2}{|c|}{ Groups } & \multirow{2}{*}{$\mathrm{p}$ value } \\
\hline & & 1 & 2 & \\
\hline \multirow{2}{*}{ Average horizontal diameter $(\mathrm{cm})$} & Right breast & 15 & 18 & 0.0016 \\
\hline & Left breast & 16.1 & 18.5 & 0.002 \\
\hline \multirow{2}{*}{ Average vertical diameter $(\mathrm{cm})$} & Right breast & 7.6 & 8 & 0.37 \\
\hline & Left breast & 7.9 & 8.1 & 0.6 \\
\hline \multirow{2}{*}{ Areola size $(\mathrm{cm})$} & Right breast & 3.8 & 4.5 & 0.001 \\
\hline & Left breast & 3.98 & 4.91 & 0.014 \\
\hline
\end{tabular}

Table 4. Variation in average diameters according to BMI.

\begin{tabular}{ccccccc}
\hline & & \multicolumn{5}{c}{ BMI } \\
\cline { 3 - 6 } & & Normal & overweight & Obesity & $\begin{array}{c}\text { Morbid } \\
\text { obesity }\end{array}$ & $\mathrm{p}$ \\
\hline $\begin{array}{c}\text { Average horizontal } \\
\text { diameter }(\mathrm{cm})\end{array}$ & Right breast & 14.8 & 20.4 & 20.8 & 17.6 & 0.01 \\
\hline $\begin{array}{c}\text { Average vertical } \\
\text { diameter }(\mathrm{cm})\end{array}$ & Left breast & 15.6 & 21 & 20.4 & 18 & 0.01 \\
\hline Right breast & 7.3 & 8.8 & 7.8 & 8.1 & 0.06 \\
Areola size $(\mathrm{cm})$ & Left breast & 7.6 & 9.3 & 8.0 & 8.3 & 0.03 \\
\hline
\end{tabular}

In Table 5, the entire breast diameters measured in this study increased statistically significantly with menopause except for the vertical diameter.

Table 6 illustrates the variations in average diameters as a function of parity. We noted an increase in the mean horizontal diameter as a function of parity. 
Table 5. Variation in mean diameters as a function of genital activity.

\begin{tabular}{ccccc}
\hline & & \multicolumn{2}{c}{ Genital activity } & \multirow{2}{*}{$\mathrm{p}$} \\
\cline { 3 - 4 } & & Not menopausal & Postmenopausal & \\
\hline Average horizontal & Right breast & 16 & 18.2 & 0.0110 \\
diameter $(\mathrm{cm})$ & Left breast & 16.5 & 19.5 & 0.0007 \\
\hline Average vertical & Right breast & 7.7 & 7.8 & 0.6 \\
diameter $(\mathrm{cm})$ & Left breast & 8 & 8.2 & 0.8 \\
\hline \multirow{2}{*}{ Areola size $(\mathrm{cm})$} & Right breast & 3.9 & 4.8 & 0.004 \\
& Left breast & 3.9 & 4.8 & 0.004 \\
\hline
\end{tabular}

Table 6. Variations in average diameters as a function of parity.

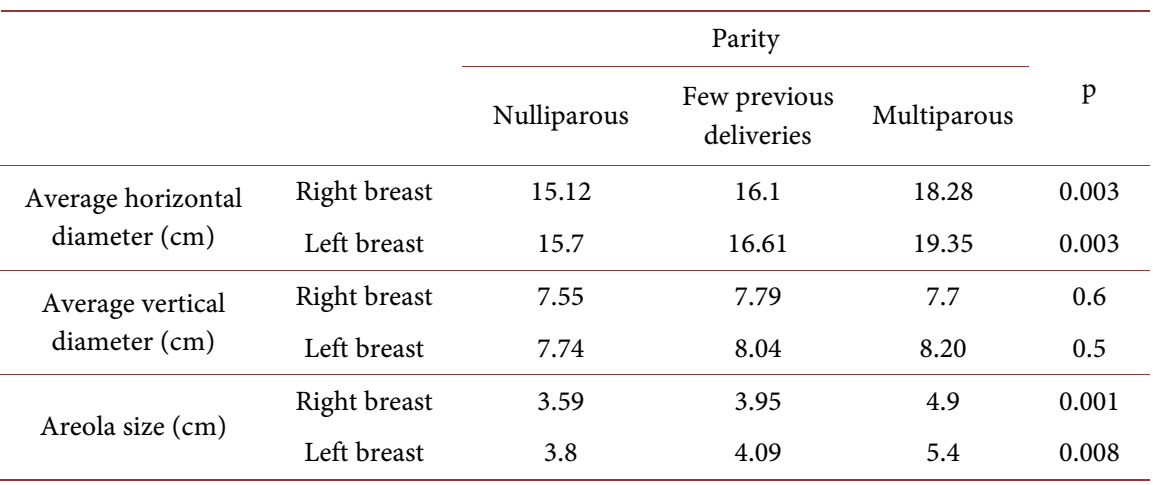

\section{Discussion}

Comparison of the two age groups 1 and 2 showed an increase in all breast diameters with age, except for vertical diameter. Brown et al. [2] had similar results with a smaller sample of 60 patients. It was the same for Kim et al. [8] who worked on the volume of the breasts. This increase in breast diameter with age is explained by the flattening, pediculization of the breast and physiological ptosis related to the morphological changes that occur with aging.

In our study, the analysis of the average BMI which was normal in the majority of our patients allowed us to note an increase in the different diameters of the breasts with weight gain. This fact was reported by several authors including Kim et al. [8], Brown et al. [2]. This increase presents a considerable peak in favor of overweight. If this increase could not be as clear in the case of obesity and morbid obesity this could be explained by the relatively low percentage of these latter groups in our sample. This could constitute a limit to our work.

The horizontal diameters and the size of the areola did not increase significantly depending on the genital activity. These results based on genital activity were found by Brown et al. [2] in 2012 who studied a sample of 89 women. In contrast, Sanuki et al. who associated measurements with the study of breast volume, found a horizontal diameter which increased significantly from $17.23 \mathrm{~cm}$ in premenopausal women to $19.08 \mathrm{~cm}$ in postmenopausal women [9]. The latter did their study on the Caucasian type. This could explain the difference between their result and ours. 
Our study found an increase in breast and areola diameters with parity. In fact, a 77.11 percentage of our patients had already had at least one child and had lower measurements than those who had at least 4 (44\%, few previous deliveries). This observation is shared by several authors, including Sanuki et al. [9]. These results are explained by the cyclical and repetitive changes depending on the parity and consequently breastfeeding. Indeed, during breastfeeding, the breast volume increases due to the increase in blood volume, secretion and development of glandular tissue. When lactation stops, the alveoli involute, the glandular tissue atrophies and is replaced by connective tissue. However, some alveoli persist.

Regarding symmetry, the average horizontal diameters of the right and left breasts are comparable, which is not the case for vertical diameters. Thus the mean horizontal diameters were $17.3 \pm 4.1 \mathrm{~cm}$ for the left breast and $16.6 \pm 4.1$ $\mathrm{cm}$ for the right breast, while the mean vertical diameter of the left breast was larger than that of the right breast with $8 \pm 2.1 \mathrm{~cm}$ for the left breast and $7.7 \pm$ $2.1 \mathrm{~cm}$ for the right breast. This lack of symmetry in vertical breast measurements could be correlated with the socio-demographic data studied.

This asymmetry of breast measurements has been noted by Brown et al. [2] in 2012 but also by Smith et al. who also did not find any significant difference in terms of volume. On the other hand, other authors have found perfect symmetry or non-significant asymmetry concerning this vertical mean diameter [10]. Regarding the difference in measurements of the size of the areola between the right and left breasts, it is contradictory to a study to another [2] [9]. Thus Sanuki noted that the average size of the areolas of the left breast was $4.4 \pm 1.6 \mathrm{~cm}$ while that of the right breast was $4.1 \pm 1.5 \mathrm{~cm}$. These values are lower than those found by Brown et al., namely 4.9 and $5 \mathrm{~cm}$ respectively for the left and right breasts [2]. Our study reveals a larger diameter for the left breast, while the opposite is found by Brown et al. in 1999. This difference could be related to the race of the patients. Indeed, Brown et al made measurements on the Caucasian type, while our measurements are made on the African type.

The average position of the nipple was $9.2 \pm 3.5 \mathrm{~cm}$ for the left breast versus $8.9 \pm 3.5 \mathrm{~cm}$ for the right breast below the horizontal passing through the middle of the lateral acromion-epicondyle line. This shows an asymmetry of position between the left and right breasts, noted by Katch et al. [7] who found similar results when working on the volume. Thus De Mey et al. [4] used a surgical technique limiting the scar in the ptoses which influence the position of the nipple. This variation in the position of the nipple could be explained by the particular distribution of fatty mass or adipose tissue in women with an excess of fat which is localized especially in the breasts, lower abdomen, hips, buttocks and thighs; one speaks of gynoid type distribution of fat [11].

\section{Conclusion}

Our results showed important influence of socio-demographic data on breast morphometry in Senegal. Taking this into account will allow better management of 
breast reduction or breast augmentation in Senegal but above all reconstruction in context of cancer resurgence in our country. In short, this work has made possible to have a two-dimensional database which will be completed by a later study based on volume.

\section{Conflicts of Interest}

The authors declare no conflicts of interest regarding the publication of this paper.

\section{References}

[1] Bricout, N. (2005) Thoracic Morphology and Breast Prosthesis. Annals of Cosmetic Plastic Surgery, 50, 441-450. https://doi.org/10.1016/j.anplas.2005.08.004

[2] Brown, N., White, J., Milligan, A., Risius, D., Ayres, B., Hedger, W. and Scurr, J. (2012) The Relationship between Breast Size and Anthropometric Characteristics. American Journal of Human Biology, 24, 158-164. https://doi.org/10.1002/ajhb.22212

[3] Brown, T.P., La, H., Ringrose, C., Hyland, R.E., Cole, A.A. and Brotherston, T.M. (1999) A Method of Assessing Female Breast Morphometry and Its Clinical Application. British Journal of Plastic Surgery, 52, 355-359. https://doi.org/10.1054/bjps.1999.3110

[4] De Mey, A. and Et Lejour, M. (1999) Breast Plastic Surgery for Enlargement and Ptosis. In: Surgical Techniques-Reconstructive and Aesthetic Plastic Surgery, Elsevier, Paris, 645-661.

[5] El-Oteify, M., Abdel Megeed, H., Ahmed, B. and El Shazl, Y.M. (2006) Assessment of the Breast Volume by a New Simple Formula. Indian Journal of Plastic Surgery, 39, 13-16. https://doi.org/10.4103/0970-0358.26897

[6] Kamina, P. (2004) Summary of Clinical Anatomy Volume III. Maloine, Paris, France.

[7] Katch, V.L., Compaigne, B., Fregdson, P., Sady, S., Katch, F.I. and Behnke, A.R. (1980) Contribution of Breast Volume and Weight to Body Fat Distribution in Females. American Journal of Physical Anthropology, 53, 93-100. https://doi.org/10.1002/ajpa.1330530113

[8] Kim, S., Kim, M. and Kim, M.J. (2013) The Affecting Factors of Breast Anthropometry in Korean Women. Breastfeeding Medicine, 9, 73-78.

[9] Sanuki, J., Fukuma, E. and Uchida, Y. (2009) Morphologic Study of Nipple-Areola Complex in 600 Breasts. Aesthetic Plastic Surgery, 33, 295-297. https://doi.org/10.1007/s00266-008-9194-y

[10] Smith Jr., D.J., Palin Jr., W.E., Katch, V.L. and Bennett, J.E. (1986) Breast Volume and Anthropomorphic Measurements: Normal Values. Plastic and Reconstructive Surgery, 78, 331-335. https://doi.org/10.1097/00006534-198609000-00008

[11] Nedungadi, T.P. and Clegg, D.J. (2009) Sexual Dimorphism in Body Fat Distribution and Risk for Cardiovascular Diseases. Journal of Cardiovascular Translational Research, 2, 321-327. https://doi.org/10.1007/s12265-009-9101-1 